\title{
Richard Allen Williams, M.D.: a Career Fighting Disparities and Fostering Equity
}

\author{
Rahn K. Bailey ${ }^{1} \cdot$ Adrienne M. Saldana $^{1} \cdot$ Andrea M. Saldana $^{1}$ (D) \\ Received: 27 April 2020 / Revised: 24 June 2020 / Accepted: 30 June 2020 / Published online: 6 July 2020 \\ (C) W. Montague Cobb-NMA Health Institute 2020
}

\begin{abstract}
This is a literature review where we acknowledge Richard Allen Williams, the first African American physician to win the John P. McGovern Compleat Physician Award, and recognize his achievements in race and ethnicity in healthcare. There have been significant advances in the diagnosis and treatment of cardiovascular disease; however, racial disparities continue to create inequity in the medical community especially for African Americans. Dr. Williams founded the Association of Black Cardiologists (ABC) in 1974 to address the misperception about, and the misdiagnosis and maltreatment of African American patients. He emphasized the importance of diversity and the non-biased approach to the treatment of all communities. This literary review further explores current racial disparities African Americans face during the COVID-19 pandemic. Granted that Dr. Williams' win is a step towards progress and change, there is much to be done to conquer the cultural divide in healthcare.
\end{abstract}

Keywords Racial disparities · Inequities · African Americans · Cardiology · COVID-19 · Award

\section{Introduction}

The Harris County Medical Society (HCMS) and the Houston Academy of Medicine (HAM) has named Dr. Richard Allen Williams winner of the John P. McGovern Compleat Physician Award at a ceremony on January 17, 2020. Dr. Williams is the first African American recipient of the award [1].

The John P. McGovern Compleat Physician Award is an annual national award, named after its first recipient, John P. McGovern. It recognizes the physician who embodies the ideals of Sir William Osler - medical excellence, humane and ethical care, commitment to medical humanities and writing, research, and harmony between the academic and medical practitioner. Dr. Williams' commitment to excellence is demonstrated by his continued contributions to the field of cardiology, excelling as a clinician in his 50 years of medical practice [2].

There has been a lot of discussion about African Americans not being acknowledged for their achievements. This is true not only in the black community, but among foreigners, international medical graduates, women, and other minority groups.

Andrea M. Saldana

andrea.saldana90@gmail.com

1 Charles R. Drew University School of Medicine, Los Angeles, CA, USA

\section{Racial Disparities in Cardiovascular Disease}

Historically, there has been a difference in cardiovascular disease (CVD) burden among racial/ethnic groups in the USA. One in every four deaths in the USA is caused by CVD. In other words, one person dies every $37 \mathrm{~s}$ [3]. In 2015, $23.5 \%$ of African Americans died from heart disease, $23.9 \%$ are male and $23.1 \%$ are female. In 2017 , heart disease at $24.2 \%$ was the leading cause of death in men of all ages and in all races and origins [4]. Heart disease at $21.8 \%$ was also the leading cause of death in women of all races and origins [5]. The best predictors of CVD are age, gender, dyslipidemia, hypertension, and diabetes. These risk factors are strongly influenced by lifestyle (dietary behaviors, physical inactivity, smoking, and adiposity). Although genetic variation plays a role in susceptibility, it cannot account solely for the difference in racial/ ethnic health disparities. [6].

In layman's terms, hypertension is high blood pressure, which increases the risk for heart disease and stroke by causing permanent damage to the heart even without having any symptoms [7]. Unfortunately, hypertension is more prevalent and develops at a younger age in African Americans than whites or Hispanics [8]. Furthermore, African Americans are more likely to have diabetes than non-Hispanic whites [7].

In $2018,17.9 \%$ of the American population was covered by Medicaid [9]. Meanwhile, 34\% of African Americans were supported by Medicaid, compared to $32 \%$ Hispanics and $15 \%$ 
whites [10]. The USA spent \$219 billion from 2014 to 2015 on heart disease alone. This includes the cost of healthcare services, medicines, and lost productivity due to death [3].

\section{Association of Black Cardiologists}

Dr. Williams founded the Association of Black Cardiologists (ABC) in 1974 to address the inequities in cardiovascular care between blacks and whites. He served as $\mathrm{ABC}$ president for 10 years [11]. He set out to form the organization because of the fact that "blacks were being misunderstood by whites in medicine," Dr. Williams said in an essay he wrote for the 60th reunion of Harvard Class 1957. In the essay, he revealed that there were articles in peer-reviewed medical journals "stating that black patients did not experience chest pain as whites did because blacks lack the intellectual capacity to perceive pain!" [12].

Dr. Williams started ABC along with 17 other dedicated medical professionals. Since its inception, ABC's membership has grown to 1800 , carrying forward the $\mathrm{ABC}$ " 18 " mission to bring special attention to the adverse impact of cardiovascular disease on African Americans, and close the healthcare disparity gap. Through the years, policy makers have looked to the $\mathrm{ABC}$ as the leading authority on issues that impact the practice of and access to cardiovascular care in all populations [13].

ABC members have published 100 studies and op-ed articles - between 2016 and the present- on the treatment of black patients [14]. In one study, "Achieving Health Equity by Normalizing Cardiac Care," Pegus et al. compared the rates of percutaneous transluminal coronary angioplasty (PTCA) for acute myocardial infarction (AMI) and for intermediate coronary syndrome (ICS), and the rates of transcatheter aortic valve replacement for aortic stenosis in white population versus black population covered by equivalent insurance. While blacks have similar prevalence rates for AMI and ICS, they experience lower rates of PTCA by $46 \%$ compared with whites. The same study found that black patients receive fewer, evidenced-based cardiac procedural care than white patients. The authors concluded that "normalizing" procedure rates in the African American community to match their disease prevalence will require education and participation from patients, providers, insurers, and advocacy organizations. The study not only stressed the importance of identifying factors that contribute to health disparities, it recommended the application of science-based care. One solution to help normalize procedure rates and decrease disparities is by providing cardiovascular registries that link to health insurance claims and electronic medical record (EMR) data. This can provide transparent information about treatment cost for various racial/ ethnic groups, enhance treatment communication and recommendation, and improve the consistency of appropriate cardiovascular procedures among patient groups [15].
Research suggests that minority patients are more likely to follow healthcare recommendations provided by healthcare workers of the same race. With this in mind, $\mathrm{ABC}$ aims to improve diversity of the health workforce via support of federal legislative efforts such as the Health Equity and Accountability Act of 2016 [13].

Dr. Williams believes in the importance of diversity considerations in healthcare and the non-biased treatment of people or communities because of their dissimilar status. A great deal of the poor and underserved communities is made up of African Americans, representing the disenfranchised population who do not receive good healthcare. As a result of poor quality care in cardiology, African Americans have worsened in morbidity or disease and could face early mortality or death [16].

The ABC's mission is to eliminate cardiovascular disparities through education, research, and advocacy. Its website http://www.abc-patient.com/ offers free digital health guides such as "7 Steps to a Healthy Heart," "Acute Coronary Syndrome: Stroke and Heart Attack Prevention," and "Cooking for your Heart and Soul" featuring recipes good for the heart. Available for purchase, when in stock, is a 40-min video "Before You Eat the Church Food, Watch This Video. "It details how unhealthy foods and sedentary lifestyles contribute to obesity and diabetes that fuel heart disease numbers [17].

\section{More Disparities}

Let us discuss racial disparities in pain assessment and treatment.

Question: Is a black person's skin thicker than a white person's skin? In a perfect world free of bias, we would all reply, "No, the perception or treatment of pain in blacks and whites is equal." In the real world, past or present, this is a rarity. A 2016 study conducted by Hoffman et al. demonstrates that there are beliefs held by laymen and those with some exposure to medical training (medical students and residents) about biological differences between blacks and whites that contribute to racial disparities in pain assessment and treatment. False beliefs dating back to the time of slavery such as the idea that blacks feel less pain than whites continue to be held by many folks today. The consequence is inaccurate pain assessment and inadequate pain treatment of African Americans. This study is the first to provide evidence that racial bias in pain perception is associated with racial bias in pain treatment recommendations [18].

Sadly, racial disparities are apparent in the midst of COVID-19 pandemic. The novel coronavirus is infecting 
and killing people all over the world. As of April 5, 2020, there are a total of 7616 deaths and 304,826 cases of COVID-19 in the USA, according to the Centers for Disease Control and Prevention (CDC) [19]. The coronavirus does not discriminate, but can the same be said for physicians and healthcare workers on the front lines?

An article published on April 2, 2020, on the NPR website reported that African Americans with symptoms of cough and fever were less likely to be tested for coronavirus, citing biotech data firm Rubix Life Sciences' reviews on recent billing information in several states. This is especially detrimental to the African Americans as they are a racial minority group with higher rates of certain diseases, such as diabetes, high blood pressure, and kidney disease. Any delay in the possible diagnosis and treatment of COVID-19 is harmful and puts them at greater risk of death because chronic illnesses can lead to more severe cases of COVID-19. On top of hypertension, coronary artery disease, heart failure, and myocardial injury are risk factors associated with worse outcomes [20]. Dr. James Hildreth, president of Meharry Medical College and an infectious disease specialist, shared his observations with NPR. He said he has not witnessed overt bias among healthcare workers, but the distribution of testing sites shows a disparity in access to medical care that has long persisted [21].

The definition of healthcare disparity is not simply defined by the difference in health outcomes based on race or ethnicity, rather it circumferences all attributable variables that lead to disproportionate access to care. The social determinants of health relevant to the current pandemic include limited job and social mobility, working frontline jobs, lack of adequate protective equipment, living in crowded housing, eating only food desserts without healthy foods, being uninsured, and relying on public transportation [22]. The widening health status gap is largely determined by race. Clyde W. Yancy, MD, in his article "COVID-19 and African Americans" referenced the Johns Hopkins University and American Community Survey, which showed that out of 131 predominant black counties in the USA, the infection rate is $137.5 / 100,000$ and the death rate is $6.3 / 100,000$. This indicated an infection rate threefold higher, and a death rate sixfold higher than that in predominantly white counties [20]. For example, in New York, black people comprise 28\% of COVID19 deaths despite representing $22 \%$ of the population, while white people accounted for $27 \%$ of deaths although they represent $32 \%$ of the population [22]. We know the most effective strategy to reduce COVID-19 infection is social distancing and self-quarantine. Being able to maintain social/physical distancing has become an issue of privilege. Much of the African American community resides in poor areas where there is simply an inability to practice social distancing [20]. Patient choice and responsibility play an essential role as well. Patients of minority communities present themselves with late self-referral due to distrust, health beliefs, and disease fatalism [22].

"Of all the forms of inequality, injustice in health care is the most inhumane."

— Martin Luther King, Jr.

\section{Conclusion}

The important and comprehensively researched book, $A n$ American Health Dilemma: A Medical History of African Americans and the Problem of Race: Beginnings to 1900, explores the origin and history of medicine in relation to intellectual and scientific racism suffered by African Americans. It starts from the time of the slave trade, and traces the evolution of racial attitudes and healthcare practices through the Civil War and Jim Crow Laws to present day. The authors, W. Michael Byrd MD and Linda A. Clayton MD, both physicians and senior research scientists at the Harvard School of Public Health, also present current statistics on racial disparities in American healthcare as a preface to an extensive and documented history of healthcare by and for blacks.

Historically, African American physicians are not given the recognition they deserve, not because they do not do quality work, but because of racial disparity. This was the theme of Dr. Williams' acceptance speech at the John P. McGovern award ceremony. He understood the significance of being the first black physician to receive the award. It indicates progress in areas of diversity, inclusion, and equity. It is a sign of change for the better that would have made Sir William Osler, the Father of Modern Medicine, proud.

Dr. Williams is now one of the superstars of Medicine, in the same league as two trailblazing cardiovascular surgeons, Dr. Michael DeBakey and Dr. Denton Cooley [23]. Dr. DeBakey was a pioneer in coronary bypass operations [24]. Dr. Cooley performed the first successful human heart transplant in the USA [18].

"If you do not give rewards or honors to the people that are deserving based on race, gender, culture, age, education, then the John P. McGovern Physician Award loses its value," Dr. Williams said in his speech at the award ceremony. He also knew the value of building strong, effective relationships throughout the healthcare community.

Rahn Kennedy Bailey, M.D., FAPA, Assistant Dean of Clinical Education at Charles R. Drew University School of Medicine and Chief Medical Officer (CMO) of the Kedren Hospital System, attended Dr. William's award ceremony in Houston, TX, on January 17, 2020.

Dr. Bailey has been a mentee of Dr. Williams for more than a decade now. When we think of a mentor and mentee, we 
automatically think of an older, wiser person helping a younger person kick-start his or her career. Dr. Williams did more than this. He valued the concept of mentorship and tried to help everyone, no matter what age, race, and gender. His focus was and always will be on justice and equity in healthcare delivery [24].

Despite his many accomplishments, Dr. Williams refuses to rest on his laurels. He wants to address the cultural divide on race and ethnicity in healthcare. "I want to do something to get rid of it and not focus on calling names. I think we can get more accomplished in this way. I am all about solidarity, unity and working together as long as people have the same aims," he stated in the August 23, 2019, issue of Cardiology magazine [25].

"Racism, whether conscious or unconscious, has been pervasive in our society since the days of slavery. I feel that is responsible for the health care disparities that we now suffer," he says. "It has been extremely difficult to erase those disparities. To do that, there has to be specific intent on the part of government and all of our citizens, and it has not been the case." [25]

Data and/or Code Availability Not applicable for that section.

\section{Compliance with Ethical Standards}

Conflict of Interest The authors declare that they have no conflict of interest.

Ethics Approval Not applicable for that section.

Consent to Participate Not applicable for that section.

Consent to Publish Not applicable for that section.

\section{References}

1. "Dr. Richard Allen Williams Receives Compleat Award." Our Weekly, ourweekly.com/news/2020/jan/24/dr-richard-allenwilliams-receives-compleat-award/.

2. Advanced Solutions International, Inc. About Us, www.hcms.org/ tmaimis/HARRIS/About/About_Us.aspx.

3. "Heart Disease Facts." Centers for Disease Control and Prevention, Centers for Disease Control and Prevention, 2 Dec. 2019, www.cdc.gov/heartdisease/facts.htm.

4. "Leading Causes of Death-All Races and Origins-Males - United States, 2017." Centers for Disease Control and Prevention, Centers for Disease Control and Prevention, 20 Nov. 2019, www.cdc.gov/ healthequity/lcod/men/2017/all-races-origins/index.htm.

5. ["Leading Causes of Death-All Races and Origins-Females United States, 2017." Centers for Disease Control and Prevention, Centers for Disease Control and Prevention, 20 Nov. 2019, www.cdc.gov/women/lcod/2017/all-races-origins/ index.htm].

6. Mozaffarian, Dariush, et al. "Beyond Established and Novel Risk Factors." Circulation, 10 June 2008, https://doi.org/10.1161/ circulationaha.107.738732.

7. "African Americans and Heart Disease, Stroke." Www.heart.org, www.heart.org/en/health-topics/consumer-healthcare/what-iscardiovascular-disease/african-americans-and-heart-disease-stroke.
8. Jamerson, Kenneth A. "The disproportionate impact of hypertensive cardiovascular disease in African Americans: getting to the heart of the issue." Wiley Online Library, John Wiley \& Sons, Ltd, 25 May 2007, https://doi.org/10.1111/j.1524-6175.2004. 03563.x.

9. Mikulic, Matej. "Medicaid Covered Share U.S. 1990-2018." Statista, 16 Sept. 2019, www.statista.com/statistics/200960/ percentage-of-americans-covered-by-medicaid/.

10. "Medicaid coverage rates for the nonelderly by race/ethnicity." The Henry J. Kaiser Family Foundation, 4 Dec. 2019, www.kff.org/ medicaid/state-indicator/rate-by-raceethnicity-3/? currentTimeframe $=0 \&$ sortModel $=\{$ "colId": "Location", "sort": "asc"\}.

11. "Richard Allen Williams, M.D., FACC." Image Alt, www. thecobbinstitute.org/faculty/richard-allen-williams-m-d-facc.

12. Williams, Richard Allen. My lifetime of pride and prejudice before, during, and after Harvard. An Invited Essay for the 60th Reunion of the Harvard Class of 1957.

13. "Advocacy." Association of Black Cardiologists, abcardio.org/ advocacy/.

14. "Published Studies and Articles by ABC Members." Association of Black Cardiologists, abcardio.org/published-by-members/.

15. Pegus, Cheryl, et al. "Achieving health equity by normalizing cardiac care.” Health Equity, Mary Ann Liebert, Inc., Publishers, 28 Dec. 2018, www.ncbi.nlm.nih.gov/pmc/articles/PMC6323589/.

16. "Richard Allen Williams, MD, FACC." Association of Black Cardiologists, 24 Apr. 2017, abcardio.org/board-of-directors/ richard-allen-williams-md-facc/.

17. Www.grahamrobertsonmiller.co.uk. "ABC Educational Resources Order Page." $A B C$, www.abc-patient.com/.

18. Hoffman KM, Trawalter S, Axt JR, Oliver MN. Racial bias in pain assessment and treatment recommendations, and false beliefs about biological differences between blacks and whites. Proceedings of the National Academy of Sciences of the United States of America vol. 2016;113(16):4296-301. https://doi.org/10.1073/pnas. 1516047113.

19. "Cases in U.S." Centers for Disease Control and Prevention, Centers for Disease Control and Prevention, 3 Apr. 2020, www. cdc.gov/coronavirus/2019-ncov/cases-updates/cases-in-us.html.

20. Yancy, Clyde W. "COVID-19, African Americans, and Health Disparities." JAMA, American Medical Association, 19 May 2020, jamanetwork.com/journals/jama/fullarticle/2764789.

21. Farmer, Blake. "The Coronavirus Doesn't Discriminate, But U.S. Health Care Showing Familiar Biases." NPR, NPR, 2 Apr. 2020, www.npr.org/sections/health-shots/2020/04/02/825730141/thecoronavirus-doesnt-discriminate-but-u-s-health-care-showingfamiliar-biases.

22. Jr, William F. Owen. "Failing Another National Stress Test on Health Disparities." JAMA, American Medical Association, 19 May 2020, jamanetwork.com/journals/jama/fullarticle/2764788.

23. "Famed Heart Surgeon Michael DeBakey Dead." CBS News, CBS Interactive, www.cbsnews.com/news/famed-heart-surgeonmichael-debakey-dead/.

24. Becker A, et al. "Denton A. Cooley, M.D., Dies at 96." TMC News, 16 Aug. 2019, www.tmc.edu/news/2016/11/denton-cooley-m-ddies-96/.

25. "Courageous Conversations: Richard Allen Williams: A Lifetime Dedicated to Diversity, Inclusion." American College of Cardiology, 23 Aug. 2019, www.acc.org/latest-in-cardiology/ articles/2019/08/18/24/42/courageous-conversations-richard-allenwilliams-a-lifetime-dedicated-to-diversity-inclusion.

Publisher's Note Springer Nature remains neutral with regard to jurisdictional claims in published maps and institutional affiliations. 